\title{
Decisions of Closed-Loop Supply Chain Based on Recycling Effort and Differential Game
}

\author{
Jingxiu Song, 1 Yuan Bian, ${ }^{1}$ and Guangdong Liu $\mathbb{D}^{2}$ \\ ${ }^{1}$ University of Chinese Academy of Sciences, Beijing, China \\ ${ }^{2}$ School of Business, Fuyang Normal University, Fuyang, China \\ Correspondence should be addressed to Guangdong Liu; 1359162826@qq.com
}

Received 6 May 2020; Revised 31 July 2020; Accepted 16 September 2020; Published 27 September 2020

Academic Editor: Xiaohua Ding

Copyright (c) 2020 Jingxiu Song et al. This is an open access article distributed under the Creative Commons Attribution License, which permits unrestricted use, distribution, and reproduction in any medium, provided the original work is properly cited.

Recycled resource and consumer satisfaction drive bicycle enterprises to take effort to recycle damaged bicycles. Considering consumers' riding experience, this paper analyzes a closed-loop supply chain where the operator sets price and recycling effort, and the supplier determines wholesale price. Rent and recycling strategies in integrated and decentralized channels are analyzed, and four types of revenue and cost-sharing contracts are compared, and the linear transfer payment-CS contract is designed to coordinate the decentralized supply chain. The results show that the consumers' concern for riding experience can encourage the operator to increase recycling effort and the operator increases the rents and recycling effort over time. Besides, the sharing deposit income among supply chain members only affects the wholesale price and does not change the decisions of rent and recovery effort. In other words, the deposit is used to adjust the profit distribution among members, and there is no difference for consumers and society.

\section{Introduction}

Shared bicycles are ideal transport for short-distance pointto-point trips providing consumers the ability to pick up a bicycle at any self-serve sharing point and return it to any other point [1]. They are viewed as an ambitious program to cut traffic, reduce pollution, and enhance the area's image as a greener and quieter pace with a better way of life [2]. China has become top ranked nation by bicycle ownership, and traffic flow and nongovernment-operated shared cycling programmers such as OFO and Mobike have flourished [3]. However, with the development of shared bicycles, it is urgent to deal with damaged bicycles which is negative for bicycle use and urban appearance. For example, a lot of consumers say that it is normal to find a bicycle which is in a good condition after sweeping two or three times. In other words, it is very possible that consumers have to look for another bicycle when the one finds the bad bike firstly which leads to low consumers' satisfaction. On the other hand, the unusable bicycles scattered around the city are not conducive to city management which damages the image of the city. Therefore, when people enjoy the convenience that shared bicycles bring, it is important to do a good job in recycling damaged bicycles.

From the perspective of company operation, the purpose is to manage efficiently bicycles in order to minimize the operation cost and the number of consumers who cannot be satisfied. According to the literature, balancing operation can be carried out in different modes, while some operators make use of the static balance $[4,5]$, some others make use of the dynamic balance $[6,7]$, or alternatively, it can be performed by considering a combination of these two balanced modes [2]. However, there is a lack of analytical research literature on recycling scrapped bicycles in terms of company operation.

The recycling of damaged bicycles means that the firm reclaims unusable bicycles then returns them which can be normal use through maintenance and scraps them which are damaged severely. For example, by July 2018, Mobike has scrapped more than 60 thousand bicycles in an environmentally friendly way and OFO recycles more than 70 thousand old waste bicycles in total (China Economic 
Herald). The larger the number of the available bicycles, the greater the possibility that consumers can find a good bicycle when they need one. The availability of bicycles influences the consumers' riding experience and then affects the demand. Obviously, consumers feel frustrated when they cannot find a bicycle when they need one. On the other hand, in order to guarantee the availability of a bicycle and high satisfaction, the firm should focus on the investment of the recycling (recycling cost) which is measured by the recycling effort. For instance, OFO has reached a strategic cooperation of the "Urban Stock Cycle Sharing Plan" with Beijing Vanke, China Circular Economy Association, and Beijing Urban Renewable Resources Service Center. Therefore, in this paper, considering consumers' experience, we assume that the more recycling effort, the higher consumers' satisfaction, then the more demand $[8,9]$.

High cost is a major obstacle to the recovery of damaged bicycles, and it is important to build a mechanism which help to reallocate profit. Many types of mechanisms are available for our references: cost sharing, revenue sharing or the combination of the two, and two-part tariff $[10,11]$. Recycling cost even exceeds the price of new bicycles because the recycling price is not high which are mostly made of ordinary materials. In other words, the enterprises may directly choose new bicycles instead of repairing and recycling discarded bicycles merely in pursuit of economic interests [12]. From the aspect of company operation, it is very stressful to bear the recycling cost by only one member and only cost sharing can enhance the enthusiasm of enterprises to recycle damaged bicycles. Hence, we try to establish a kind of mechanism between the bicycle operator and supplier to coordinate the bikesharing supply chain on the basis of cost sharing. In addition, the recycling effort is subject to marginally diminishing return model by the cost as a convex function that takes the quadratic form in terms of characteristics of recycling investment [13].

The above discussions on bicycle recycling raise the following research questions: (i) What are the optimal pricing and recycling effort strategies in integrated/decentralized setting? (ii) What are the differences among the four types of revenue sharing-cost sharing contracts (RSCS), which are the rent and deposit sharing (UP-CS), only rent sharing (P-CS) and only deposit sharing (U-CS), and cost sharing (CS)? (iii) How to design a contract to perfectly coordinate the decentralized supply chain? To answer these questions, we consider a two-echelon bike sharing supply chain in a dynamic setting, of which the operator determines rent and recycling effort, and the supplier sets the wholesale price. We first characterize static recycling effort strategies in integrated and decentralized modes, respectively, then compare and analyze the corresponding solutions under both scenarios. A linear transfer payment based on cost sharing (CS) contract is designed to coordinate the dynamic supply chain.

The major contributions of this paper are as follows: first, we develop an analytical bike sharing supply chain model considering recycling which so far has not been studied. Secondly, we investigate four different revenue-cost sharing mechanisms and compare them. Finally, we propose a linear transfer payment contract to coordinate the supply chain.

The remainder of this paper is organized as follows: Section 2 reviews the related literature and Section 3 describes the formulation of model. The corresponding equilibrium strategies under two scenarios are presented in Section 4 . The revenue sharing-cost sharing contracts are compared and the supply chain is coordinated in Section 5. Section 6 shows the numerical analysis. Finally, Section 7 concludes the paper.

\section{Literature Review}

We review the literature closely related to our research. The first body of research examines the Bike Sharing System (BSS). In 1965, the Bike Sharing System (BSS), which originated in Amsterdam, evolved from the first generation of bicycle to the shared bicycle system based on IT systems. DeMaio gave a detailed overview of the history of shared bicycle development [14]. Ricci presented a more comprehensive literature review of the shared bicycle system [15]. From the above review, most of the early literature focused on the history of shared bicycles, promotional factors and policies, and security issues. Some recent literature has focused on operational design on the strategic and operational levels.

In terms of strategic design, its research includes site network design and site capability design (decision of total number of vehicles and parking spaces in the site). Lin and Yang [16] proposed a model of determining the number, location, and lane network of stations, which takes into account the concerns of consumers and bicycle operators. Nair and Miller-Hooks [17] did a similar study in Washington City. In the extended study, the bicycle inventory decision for each site in the planning and design of the BSS site was considered. Similarly, Martinez et al. [18] used a mixed-integer programming method to calculate the location of the site and the number of vehicles required. Park and Sohn [19] studied how to minimize the amount of short-haul travel of private cars by the design of sharing bicycle stations. Yan et al. [2] applied time-space network models to determine the locations of bike rental stations, bike fleet allocation, and bike routing. In addition, Kaltenbrunner et al. [20], Bordagaray et al. [21], and Yang et al. [22] used data analysis method to explore the temporal and spatial patterns of bicycle's use and their impacts on public transportation system.

In terms of operational design, BSS meets the highest consumers' demand and minimizes the operating cost while meeting minimum service level. The main research includes two aspects: the forecast of demand and rebalancing of vehicles between stations. Demand forecasting is often based on operational data from which some BSS published on the network to predict future demand, vehicle availability, etc., such as Pucher et al. [23] and Kadri et al. [4]. The balance of the vehicles between the stations is further divided into a static balance problem (SBP) and a dynamic balance problem (DBP). The static balance problem assumes that there are very few vehicles in use, such as when rebalancing 
at night. Most of these problems are solved by using mixedinteger programming, but the objective functions are different. It usually can be sorted by single-scheduled truck problem and multischeduled truck problem. Chemla et al. [24] studied single-scheduled truck problem while Kaspi et al. [25] did multidistribution truck problem.

However, there is still lack of research on how to recycle the damaged vehicles, repair, and reinvest in the operation. The recycling problem is mainly studied as a reverse part of closed-loop supply chain.

Some scholars have done relevant research on the recycling of waste electronic products. In the field of competition about product and recycling, Wang et al. [26] studied a hybrid closed-loop supply chains: one is the CLSC containing the manufacturer and the retailer; the other is the CLSC containing the remanufacturer and the retailer. Considering product and recycling channel competition, they designed price strategies under three scenarios. Wu and Kao [27] developed price and quality strategies by the assumption of quality affecting on the recycling cost and designed two cooperative mechanisms between original equipment manufacturer and the independent remanufacturer. Hong et al. [28] investigated production quantities and return rates competition of the new and remanufactured products and analyzed the effect of licensing fee on remanufacturing. Based on the carbon emissions, $\mathrm{He}$ et al. [29] developed price and recycling strategies in a dual-channel closed-loop supply chain considering consumer free riding and e-commerce tax. Giri et al. [30] constructed a closedloop supply chain about both the forward dual-channel and reverse dual-channel chain. They derived analytically the price and return product collection decisions for the supply chain under five different scenarios. Miao et al. [31] developed a closed-loop supply chain with trade-ins, which analyzed the impacts on different models including the centralized collection (Model C), the retailer collection (Model R), and the manufacturer collection (Model M). Liu et al. [32] designed three kinds of dual-recycling channels: OEM and retailer dual collecting model, retailer and third party dual collecting model, and OEM and third party dual collecting model. They found that the OEM and retailer dual collecting model is the best option for the OEM regardless of the competition intensity.

In addition, the other stream is the contract design to improve the reverse supply chain performance. Zheng et al. [33] made price and collecting effort decision under complete and incomplete information scenarios then introduced a two-part tariff contract to improve the reverse supply chain performance. Modak et al. [34] analyzed the effects of recycling and product quality level on pricing decision under three collection activities (retailer, manufacturer, and third party). They also introduced subgame perfect equilibrium and alternative offer bargaining strategy to improve the reverse supply chain performance. Xu et al. [35] investigated the optimal retail price, reduction rate, and recycling rate considering emission reduction. They used the method of Nash theory to solve the profit distribution in two periods by introducing the bargaining behavior. Based on an online/ offline dual channel, Xie et al. [36] made the optimal online/ offline price, wholesale price, and advertising investment decision and developed a revenue-sharing mechanism to resolve channel conflict. Choi et al. [37] examined the performance of different CLSC channel leaderships (a retailer, a collector, and a manufacturer) and found that the retailer-led model gave the most effective CLSC. They designed a two-part tariff contract CLSC and a pair wise revenue and cost sharing (PRCS) contract to coordinate the CLSC. Hu et al. [38] designed five typical contracts to coordinate the reverse supply chain with strategic recycling behaviors of consumers and drew a comparison among the contracts. Kaya [39] determined the optimal incentive value and production quantities in a stochastic demand then analyzed contracts to coordinate the decentralized systems.

The above literature studies discuss the pricing decision and coordination of closed-loop supply chain for product recycling. The recycling, repair, and redistribution of bicycles are different from the recovery of ordinary products. The recycling effort of bicycles increases the revenue by affecting the consumers' feelings, while the recovery of common products brings direct cost savings. From this perspective, Saha et al. [40] induced the "green concern level" (GCL) to study the optimal retailer investment in green operations. De Giovanni [8] considered consumers' environmental consciousness to discuss the closed-loop supply chain coordination. Taboubi [9] and Zhang et al. [11] built the brand goodwill of the consumer to decide the price and the advertising effort. The key difference from theirs is that we focus on presenting optimal rent and recycling effort of the operator and designing an effective contract to improve channel performance.

\section{Model Description}

In the section, we consider a two-echelon supply chain consisting of a bicycle supplier $s$ and a bicycle operator $o$. The operator procures bicycles from the supplier and provides consumers with riding service. On the other hand, the operator makes effort to recycle and maintain the damaged bicycles to enhance the degree of consumers' satisfaction. We assume that the supplier decides the dynamic wholesale price $w(t)$ and the operator determines the dynamic rent $p(t)$ and static effort $g$. This may stem from the fact that the dynamic investment about recycling effort is difficult for the operators to implement. The structure of bike-sharing closed-loop supply chain is shown in Figure 1.

Let $G(t)$ denote consumers' riding experience (bicycle's quality and availability) which is mainly affected by the recycling effort. On the other hand, the experience decays with time due to the memory characteristics. According to Zhang et al. [11], the stock of experience evolves as follows:

$$
\begin{aligned}
& G(t)=\lambda g-\rho G(t), \\
& G(0)=G_{0}>0,
\end{aligned}
$$

where $\lambda$ is the recycling effort and $\lambda>0, \rho>0$ reflects the decay rate of consumers' memory about riding experience (hereafter, we call it the decay rate for short), and $G_{0}>0$ is the initial consumers' experience. 


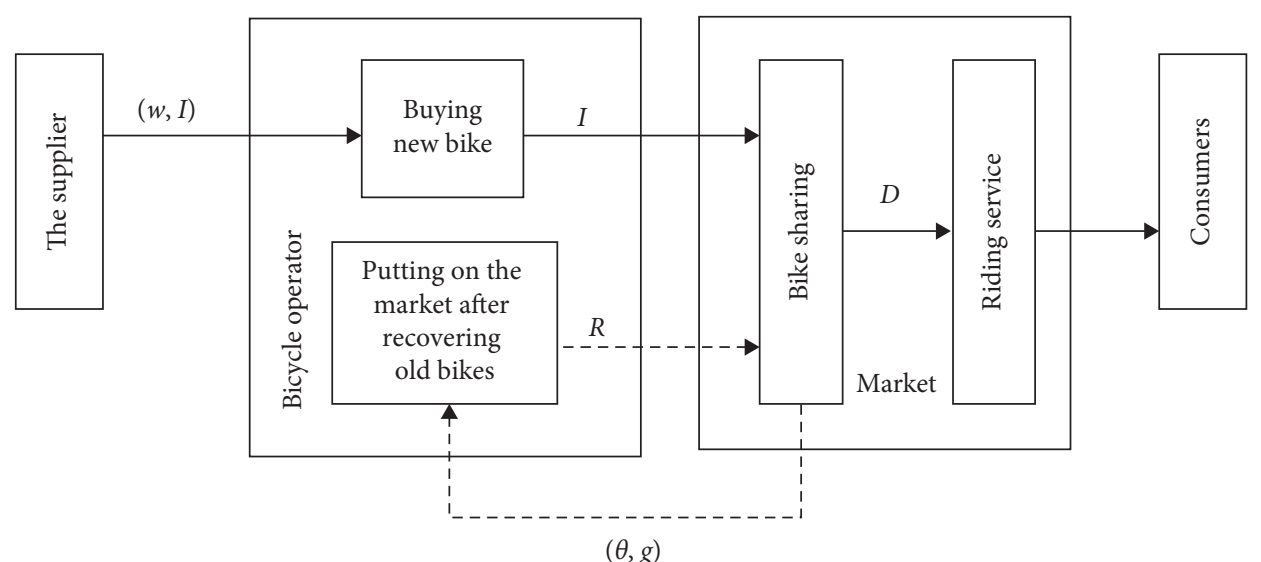

FIgURE 1: The structure of bike-sharing closed-loop supply chain.

The consumers' riding experience and price which consists of deposit and rent affect the demand of bicycles where a great experience has a positive effect on bicycle usage, while high price of the service may lessen the demand. Hence, the market demand rate is a function of the experience, rent, and deposit. According to Saha et al. [40], the market demand is as follows:

$$
D(t)=\eta+\alpha G(t)-\beta p(t)-u,
$$

where $\eta>0$ is the basic market potential, $\beta>0$ represents the sensitivity of rent to the demand rate, $\alpha>0$ reflects the sensitivity of the experience, and $u$ represents the deposit which is an exogenous variable.

We assume that the quantity of the damaged bicycles is proportional to the market demand and take the damage rate as $\theta$. Some of these damaged bicycles are released again after repairing while some are scrapped. It is supposed that the operator buys bicycle which is equal to the scrapped. More effort leads to more reusing after repairing and less repurchasing. According to Saha et al. [40], we assume that the reusing proportion of the damaged bicycles is $\left(1-e^{-\gamma g}\right)$, where $\gamma$ is the sensitivity parameter. The functions of the reusing rate $R(t)$ and the repurchasing rate $I(t)$ are as follows:

$$
\begin{aligned}
R(t) & =\theta D(t)\left(1-e^{-\gamma g}\right), \\
I(t) & =\theta D(t) e^{-\gamma g} .
\end{aligned}
$$

As for the cost structure, we assume that the manufacturing cost is constant and normalized to 0 to better analyze the impacts of rent and recycling maintenance effort on the revenue of single-vehicle supply chain. The operator only considers the cost of providing the service of recycling and repairing bicycles. These assumptions can simplify the model and facilitate the solution.

In accordance with a great deal of previous literature $[6,11]$, the cost function about the effort is assumed to be quadratic, i.e.,

$$
C(g)=\frac{k g^{2}}{2},
$$

where $k>0$ is an investment parameter. The quadratic function indicates that each additional increment of recycling effort becomes more difficult, and hence more cost is to be achieved, which is directly linked to diminishing return from investment. We assume that the supplier has no production cost.

Assuming an infinite time horizon, a positive discount rate $\Delta$, the bicycle operator's objective function is as follows:

$$
J_{o}=\int_{0}^{\infty} e^{-\Delta t}\left((u+n p(t)) D(t)-w(t) I(t)-\frac{k g^{2}}{2}\right) \mathrm{d} t,
$$

and the bicycle supplier's objective function is as follows:

$$
J_{s}=\int_{0}^{\infty} e^{-\Delta t}\left(w(t) \theta(\eta+\alpha G(t)-\beta p(t)-u) e^{-\gamma g}\right) \mathrm{d} t .
$$

The term $u+n p(t)$ inside equation (5) is o's marginal revenue and consists of the deposit $u$ and rent $n p(t)$, where $n$ represents the conversion between the rent and the deposit. The term $w(t) I(t)$ is the purchase cost for the operator while the revenue for the supplier. We assume that the effort is determined first then the whole price and the rent. In other words, the dynamic variables are decided on the basis of static variables. All notations are listed in Table 1.

\section{Equilibrium Strategies}

This section derives the equilibrium decisions under two scenarios: the centralized model and the decentralized model. Moreover, this section explores the impacts of parameters $(k, \alpha, \lambda, \rho$, and $u)$ on the equilibrium results and compares the equilibrium decisions between the two scenarios.

4.1. Integrated Scenario. We begin with a benchmark where the supplier and the operator are vertically integrated as a whole. The objective is to find the optimal rent and recycling effort while maximizing the SC profit. The dynamic optimization problem for the integrated channel is formulated as 
TABLE 1: Main parameters and notations.

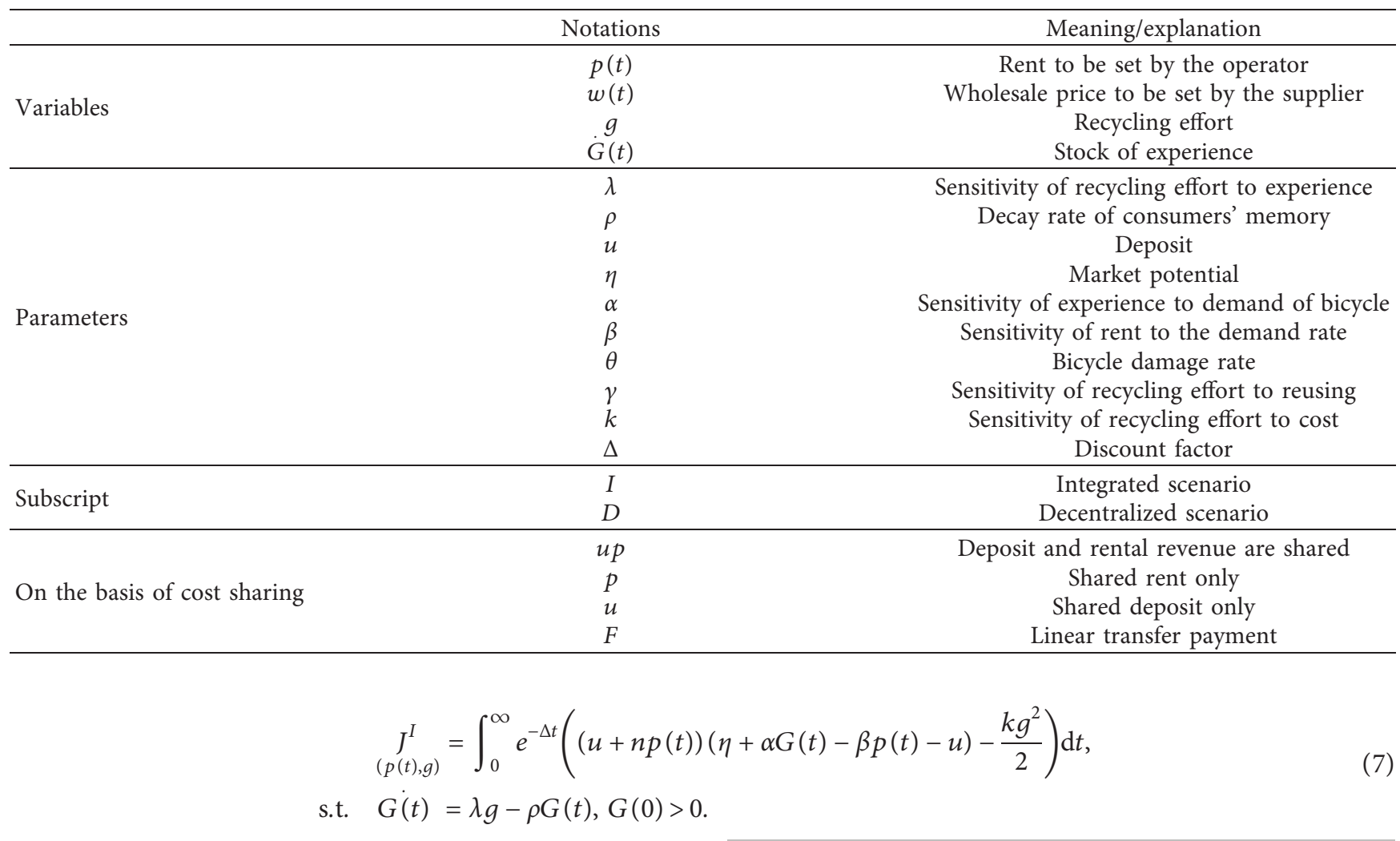

Proposition 1. Under the integrated scenario, the supply chain profit function is concave in the recycling effort if $n \alpha^{2} \lambda^{2}<k \beta\left(\Delta^{2}+3 \Delta \rho+2 \rho^{2}\right)$; hence by holding the condition, there are unique optimal combination of decision variables that maximizes the profit:

$$
\begin{aligned}
& g^{I}=\frac{\lambda \alpha\left((\Delta+2 \rho)(n(\eta-u)+u \beta)+n \Delta \alpha G_{0}\right)}{2 k \beta\left(\Delta^{2}+3 \Delta \rho+2 \rho^{2}\right)-2 n \alpha^{2} \lambda^{2}}, \\
& p^{I}=\frac{e^{-\rho t}\left(e^{\rho t}-1\right) g^{I} n \alpha \lambda+\rho\left(n\left(\eta-u+e^{-\rho t} \alpha G_{0}\right)-u \beta\right)}{2 n \beta \rho} .
\end{aligned}
$$

Ther experience
$G=G_{0} e^{-\rho t}+\left(\lambda g^{I}\left(1-e^{-\rho t}\right) / \rho\right)$.

trajectory

The process is proved in Appendix.

From Proposition 1, we obtain that the rent is state-dependent and, specifically, $\left(\partial p^{I} / \partial G\right)=(\alpha / 2 \beta)>0$. These inequalities demonstrate that the operator can increase rent according to the consumers' experience stock without damaged bicycle demand. Naturally, the greater the initial experience, the higher the rent because $\left(\partial p^{I} / \partial G_{0}\right)>0$. The recycling effort is reduced with worse initial experience because $\left(\partial g^{I} / \partial G_{0}\right)>0$. The low consumers' initial experience means a large number of damaged bicycles in the market; then it is difficult for the operator to repair bicycles from the damaged ones to the intact ones. The operator chooses to launch new bicycles instead of recycling the old ones because of the temporary high cost and the myopic characteristics of the operator. With the conclusion, we can explain this phenomenon that a large number of damaged bicycles are in a state of neglect.

The operator sets high rent because small cost sensitivity factor allows the operator to invest less recycling effort which helps the consumers to do a better experience because $\left(\partial p^{I} / \partial k\right)<0,\left(\partial g^{I} / \partial k\right)<0$. The rent and the recycling effort can increase with the sensitivity of recycling effort to experience because $\left(\partial p^{I} / \partial \lambda\right)>0, \quad\left(\partial g^{I} / \partial \lambda\right)>0$. The result suggests that a large $\lambda$ means a high effort contribution and generates a large effort investment, which improves the consumers' experience and allows for a high rent. Large forgetting effect deters the investment in recycling effort as the accumulation of stock of consumers' experience becomes a difficult target because $\left(\partial g^{I} / \partial \rho\right)<0$. Large sensitivity of experience to the demand encourages the operator to invest recycling effort, improves consumers' experience, and increases demand of bicycles because $\left(\partial g^{I} / \partial \alpha\right)>0$.

When $\beta<n$, the operator increases recycling effort facing low deposit which contributes to great consumers' experience because $\left(\partial g^{I} / \partial u\right)<0$. Also, the lower deposit stimulates the operator to set high rent to keep profit $\left(\partial p^{I} / \partial u\right)<0$. When $\beta>n$, low deposit leads to little recycling effort $\left(\left(\partial g^{I} / \partial u\right)>0\right)$. In addition, the damage rate has no effect on the recycling effort and rent decisions. More detailed analysis can be seen in the numerical analysis part.

4.2. Decentralized Scenario. In this section, the operator determines the recycling effort firstly as a Stackelberg leader; 
subsequently, the supplier sets the wholesale price. Finally, the operator sets the rent. And the optimal decisions are independently determined to maximize their own profit. Profits of the members are separately given by

$$
\underset{\substack{o \\(p(t), g)}}{J_{o}}=\int_{0}^{\infty} e^{-\Delta t}\left((u+n p(t)) D(t)-w(t) I(t)-\frac{k g^{2}}{2}\right) \mathrm{d} t
$$

$$
\underset{w(t)}{J_{s}^{D}}=\int_{0}^{\infty}\left(w(t) \theta(\eta+\alpha G(t)-\beta p(t)-u) e^{-\gamma g}\right) \mathrm{d} t
$$

$$
\text { s.t. } G(t)=\lambda g-\rho G(t), G(0)>0 \text {. }
$$

We use backward induction method to solve this sequential move game. The optimal results are presented in Proposition 2.

Proposition 2. Under the decentralized SC, the supply chain profit function is concave in the recycling effort if $n \alpha^{2} \lambda^{2}<4 k \beta\left(\Delta^{2}+3 \Delta \rho+2 \rho^{2}\right)$; hence, by holding the condition, the equilibrium rent, wholesale price, and recycling maintenance effort are as follows:

$$
\begin{aligned}
& g^{D}=\frac{\lambda \alpha\left((\Delta+2 \rho)(n(\eta-u)+u \beta)+n \Delta \alpha G_{0}\right)}{8 k \beta\left(\Delta^{2}+3 \Delta \rho+2 \rho^{2}\right)-2 n \alpha^{2} \lambda^{2}}, \\
& p^{D}=\frac{3 e^{-\rho t}\left(e^{\rho t}-1\right) g^{D} n \alpha \lambda+\rho\left(3 n\left(\eta-u+e^{-\rho t} \alpha G_{0}\right)-u \beta\right)}{4 n \beta \rho}, \\
& w^{D}=\frac{e^{\gamma g^{D}-\rho t}\left(\left(e^{\rho t}-1\right) g^{D} n \alpha \lambda+\rho\left(e^{\rho t}(n \eta-n u+u \beta)+n \alpha G_{0}\right)\right)}{2 \beta \theta \rho} .
\end{aligned}
$$

Meanwhile, the experience over time is $G=G_{0} e^{-\rho t}+\left(\lambda g^{D}\left(1-e^{-\rho t}\right) / \rho\right)$.

The process is proved in Appendix.

The conclusions about the rent and recycling effort in the integrated scenario also apply to the decentralized scenario. In addition, we try to get conclusions about the wholesale price under the decentralized scenario. A good experience means the good bicycle condition and distribution in the market, so the operator reduces the purchase from the supplier under this condition. In order to keep profit, the supplier increases the wholesale price passively with the fall of bicycle demand because $(\partial w / \partial G)>0$. The initial consumers' experience has the similar effect on the wholesale price as the state variable because $\left(\partial w / \partial G_{0}\right)>0$.

From a cost perspective, small cost sensitivity encourages the operator to pay more for the recycling effort which lowers the demand for new bicycle. With sales reduction, the supplier chooses to increase wholesale price to maintain profits because $(\partial w / \partial k)<0$. Large sensitivity of experience to demand increases the total demand as well as the new bicycles and the supplier sets high wholesale prices as a result of a greater voice because $(\partial w / \partial \alpha)>0$. When $\beta<n$, the wholesale price decreases with the deposit. In addition, the supplier adjusts the wholesale price based on the damage rate of the bicycles.

By simple algebraic calculations, we obtain $g_{I}-g_{D}>0$ and $D_{I}-D_{D}>0$. These results indicate that the optimal recycling effort is less in decentralized scenario than that in integrated scenario, which leads to worse experience and less demand. In other words, the consumers can get a better riding experience and enjoy the bicycle service in integrated scenario. We further observe that the SC profits are less because of the usual problem generated by double marginalization in decentralized scenario with $J_{I}-J_{D}>0$. Therefore, it is necessary to design a contract to improve the performance of supply chain.

\section{Coordination Analysis}

Since recycling cost is the main component of the operator's costs, we design a cost-sharing mechanism that the supplier will share a part of recycling cost with the operator to reduce the burden of recycling investment. In the cost sharing contract, $\left(1-\varphi_{2}\right)$ is the cost-sharing rate that the supplier offers, and the operator just needs to undertake $\varphi_{2}$ of the recycling investment. That is amount that the investment coefficient of the recycling drops to $\varphi_{2} k$ from $k$ for the operator. The recycling effort cost that the supplier shares is $\left(\left(1-\varphi_{2}\right) \mathrm{kg}^{2} / 2\right)$ and that the operator undertakes is $\left(\varphi_{2} \mathrm{~kg}^{2} / 2\right)$.

Based on this mechanism, we establish a revenue-sharing contract game model and a transfer-payment contract game model to coordinate the distribution of profits. The core idea is that the operator as the leader encourages the supplier to participate in the bicycle sharing supply chain.

5.1. Revenue Sharing-Cost Sharing Contracts (RSCS). Since the operator's revenue consists of the rent and the deposit, we discuss the revenue sharing under three kinds of conditions: rent and deposit sharing (UP-CS), only rent sharing (P-CS), and only deposit sharing (U-CS). We assume that the cost-sharing rate which the operator undertakes should not be less than a certain value as result of the leading role $\varphi_{2}>\left(n \alpha^{2} \lambda^{2} /\left(4 k \beta\left(\Delta^{2}+3 \Delta \rho+2 \rho^{2}\right)\right)\right)$.

5.1.1. Deposit and Rental Revenue Shared-CS. In this section, the sharing revenue is rent and deposit and the operator's share of its revenue is $\varphi_{1}$. The supplier receives a fraction 
$\left(1-\varphi_{1}\right)$ of the operator's revenue with $0<\varphi_{1}<1$. Under a deposit and rental revenue-sharing contract, the profits of the supplier and operator are as follows:

$$
\begin{aligned}
\underset{c}{\left.J_{o}^{u p}(t), g\right)} & =\int_{0}^{\infty} e^{-\Delta t}\left(\varphi_{1}(u+n p(t)) D(t)-w(t) I(t)-\frac{\varphi_{2} k g^{2}}{2}\right) \mathrm{d} t, \\
J_{s(t)}^{u p} & =\int_{0}^{\infty} e^{-\Delta t}\left(\left(1-\varphi_{1}\right)(u+n p(t)) D(t)+w(t) I(t)-\frac{\left(1-\varphi_{2}\right) k g^{2}}{2}\right) \mathrm{d} t,
\end{aligned}
$$

s.t. $\quad G(t)=\lambda g-\rho G(t), G(0)>0$.

We use backward induction method to solve this sequential move game. The optimal results are presented in Proposition 3.
Proposition 3. Under the UP-CS contract, the equilibrium rent, wholesale price, and recycling effort are as follows:

$$
\begin{aligned}
g^{u p} & =\frac{\lambda \alpha\left((\Delta+2 \rho)(n(\eta-u)+u \beta)+n \Delta \alpha G_{0}\right) \varphi_{1}}{2\left(k \beta\left(\Delta^{2}+3 \Delta \rho+2 \rho^{2}\right)\left(1+\varphi_{1}\right)^{2} \varphi_{2}-n \alpha^{2} \lambda^{2} \varphi_{1}\right)}, \\
p^{u p} & =\frac{e^{-\rho t}\left(\left(e^{\rho t}-1\right) g^{C u p} n \alpha\left(1+2 \varphi_{1}\right)+\rho\left(n \alpha G_{0}\left(1+2 \varphi_{1}\right)+e^{\rho t}\left(n(\eta-u)\left(1+2 \varphi_{1}\right)-u \beta\right)\right)\right)}{2 n \beta \rho\left(1+\varphi_{1}\right)}, \\
w^{u p} & =\frac{e^{\gamma g^{C u p}-\rho t}\left(\left(e^{\rho t}-1\right) g^{C u p} n \lambda \alpha+\left(n \alpha G_{0}+e^{\rho t}(n(\eta-u)+u \beta)\right) \rho\right) \varphi_{1}^{2}}{\beta \theta \rho\left(1+\varphi_{1}\right)} .
\end{aligned}
$$

From Proposition 3, we can observe that high costsharing ratio $\varphi_{2}$ urges the operator to lower recycling effort owing to $\left(\partial g / \partial \varphi_{2}\right)<0$, which leads to bad experience and the decline of demand. At the same time, the operator sets a low rent actively to compensate for the decreasing demand with $\left(\partial p / \partial \varphi_{2}\right)<0$. These results indicate that consumers' rental payment and riding experiences are affected by the costsharing ratio among enterprises.

5.1.2. Shared Only Rent-CS. In this section, the sharing revenue is only rent and the operator's share of its revenue is $\varphi_{1}$. The supplier receives a fraction $\left(1-\varphi_{1}\right)$ of the operator's rent revenue with $0<\varphi_{1}<1$. Under the only rent revenue-sharing contract, the profits of the supplier and operator are as follows:

$$
\begin{aligned}
& \underset{(p(t), g)}{J_{o}^{p}}=\int_{0}^{\infty} e^{-\Delta t}\left(\left(u+\varphi_{1} n p(t)\right) D(t)-w(t) I(t)-\frac{\varphi_{2} k g^{2}}{2}\right) \mathrm{d} t, \\
& \underset{w(t)}{J_{s}^{p}}=\int_{0}^{\infty} e^{-\Delta t}\left(\left(1-\varphi_{1}\right) n p(t) D(t)+w(t) I(t)-\frac{\left(1-\varphi_{2}\right) k g^{2}}{2}\right) \mathrm{d} t .
\end{aligned}
$$

We use backward induction method to solve this sequential move game. The optimal results are presented in Proposition 4.

Proposition 4. Under the P-CS contract, the equilibrium rent, wholesale price, and recycling maintenance effort are as follows:

$$
\begin{aligned}
g^{p} & =\frac{\lambda \alpha\left((\Delta+2 \rho)(n(\eta-u)+u \beta)+n \Delta \alpha G_{0}\right) \varphi_{1}}{2\left(k \beta\left(\Delta^{2}+3 \Delta \rho+2 \rho^{2}\right)\left(1+\varphi_{1}\right)^{2} \varphi_{2}-n \alpha^{2} \lambda^{2} \varphi_{1}\right)}, \\
p^{p} & =\frac{e^{-\rho t}\left(\left(e^{\rho t}-1\right) g^{C p} n \alpha\left(1+2 \varphi_{1}\right)+\rho\left(n \alpha G_{0}\left(1+2 \varphi_{1}\right)+e^{\rho t}\left(n(\eta-u)\left(1+2 \varphi_{1}\right)-u \beta\right)\right)\right)}{2 n \beta \rho\left(1+\varphi_{1}\right)}, \\
w^{p} & =\frac{e^{\gamma g^{C p}-\rho t}\left(n \alpha\left(\rho G_{0}-\lambda g\right) \varphi_{1}^{2}+e^{\rho t}\left(n \varphi_{1}^{2}(\alpha \lambda g+\eta \rho)+u \rho\left(\beta-n \varphi_{1}^{2}\right)\right)\right)}{\beta \theta \rho\left(1+\varphi_{1}\right)} .
\end{aligned}
$$


Comparing the UP-CS and the P-CS, the supplier sets a lower wholesale price under the UP-CS due to the sharing deposit income $\left(w^{u p}<w^{p}\right)$. If the operator does not share a portion of the deposit, the supplier will increase the wholesale price. The revenue sharing ratio has a direct effect on the value of rent and an indirect effect through influencing the wholesale price. These two effects are offset, and the two rents are equal $\left(p^{u p}=p^{p}\right)$. Similarly, the recycling efforts are also equal $\left(g^{u p}=g^{p}\right)$. These results indicate that the value of the rent and the recycling effort are not affected whether or not the operator and the supplier share the deposit. In other words, there is no difference for consumers between UP-CS and P-CS.

5.1.3. Shared Only Deposit-CS. In this section, the sharing revenue is only deposit and the operator's sharing ratio is $\varphi_{1}$. The supplier receives a fraction $\left(1-\varphi_{1}\right)$ with $0<\varphi_{1}<1$.
Under the only deposit revenue-sharing contract, the profits of the supplier and operator are

$$
\begin{aligned}
\underset{c}{\left.J_{o}^{u}(t), g\right)} & =\int_{0}^{\infty} e^{-\Delta t}\left(\left(\varphi_{1} u+n p(t)\right) D(t)-w(t) I(t)-\frac{\varphi_{2} k g^{2}}{2}\right) \mathrm{d} t, \\
J_{w(t)}^{u} & =\int_{0}^{\infty} e^{-\Delta t}\left(\left(1-\varphi_{1}\right) u D(t)+w(t) I(t)-\frac{\left(1-\varphi_{2}\right) k g^{2}}{2}\right) \mathrm{d} t .
\end{aligned}
$$

We use backward induction method to solve this sequential move game. The optimal results are presented in Proposition 5.

Proposition 5. Under the $U-C S$ contract, the equilibrium rent, wholesale price, and recycling maintenance effort are as follows:

$$
\begin{aligned}
& g^{u}=\frac{\lambda \alpha\left((\Delta+2 \rho)(n(\eta-u)+u \beta)+n \Delta \alpha G_{0}\right)}{8 k \beta\left(\Delta^{2}+3 \Delta \rho+2 \rho^{2}\right) \varphi_{2}-2 n \alpha^{2} \lambda^{2}}, \\
& p^{u}=\frac{\rho(3 n(\eta-u)-u \beta)+3 n \alpha e^{-\rho t}\left(\left(e^{\rho t}-1\right) g^{C u} \lambda+\rho G_{0}\right)}{4 n \beta \rho}, \\
& w^{u}=\frac{e^{\gamma g-\rho t}\left(\left(e^{\rho t}-1\right) g n \lambda \alpha+\rho\left(n \alpha G_{0}+e^{\rho t}\left(n(\eta-u)+u \beta\left(2 \varphi_{1}-1\right)\right)\right)\right)}{2 \beta \theta \rho} .
\end{aligned}
$$

It can be seen that under $\mathrm{U}-\mathrm{CS}$, the recycling effort and rents are independent of the revenue sharing ratio while the wholesale price is affected by the revenue sharing ratio.

5.1.4. CS $\left(\varphi_{1}=1\right)$. The supplier only shares a part of the cost and the profits of the supplier and operator are as follows:

$$
\begin{aligned}
\underset{(p(t), g)}{J_{o}^{C}} & =\int_{0}^{\infty} e^{-\Delta t}\left((u+n p(t)) D(t)-w(t) I(t)-\frac{\varphi_{2} k g^{2}}{2}\right) \mathrm{d} t, \\
\underset{w(t)}{J_{s}^{C}} & =\int_{0}^{\infty} e^{-\Delta t}\left(w(t) I(t)-\frac{\left(1-\varphi_{2}\right) k g^{2}}{2}\right) \mathrm{d} t .
\end{aligned}
$$

We use backward induction method to solve this sequential move game. The optimal results are presented in Proposition 6.

Proposition 6. Under the CS contract, the equilibrium rent, wholesale price, and recycling maintenance effort are

$$
\begin{aligned}
g^{C} & =\frac{\lambda \alpha\left((\Delta+2 \rho)(n(\eta-u)+u \beta)+n \Delta \alpha G_{0}\right)}{8 k \beta\left(\Delta^{2}+3 \Delta \rho+2 \rho^{2}\right) \varphi_{2}-2 n \alpha^{2} \lambda^{2}}, \\
p^{C} & =\frac{\rho(3 n(\eta-u)-u \beta)+3 n \alpha e^{-\rho t}\left(\left(e^{\rho t}-1\right) g^{C} \lambda+\rho G_{0}\right)}{4 n \beta \rho}, \\
w^{C} & =\frac{e^{\gamma g^{C}-\rho t}\left(\left(e^{\rho t}-1\right) g^{C} n \lambda \alpha+\rho\left(n \alpha G_{0}+e^{\rho t}(n(\eta-u)+u \beta)\right)\right)}{2 \beta \theta \rho} .
\end{aligned}
$$

Comparing the $\mathrm{U}-\mathrm{CS}$ and the CS, the rent and recycling effort are equal $\left(p^{u}=p^{C}, g^{u}=g^{C}\right)$ while wholesale prices are not equal $\left(w^{u}<w^{C}\right)$. This conclusion is similar to the comparison between UP - CS and P - CS. 
Proposition 7. It is assumed that the rental revenue is more than the deposit revenue, so the operator obtains more revenue under $U-C S$ than that under $P-C S$. As a result, the operator has more funds to invest in recycling effort $\left(g^{p}<g^{u}\right)$ which leads to better experience. At this point, the operator will set higher rents $\left(p^{p}<p^{u}\right)$. However, the supplier compensates for the reduction in revenue distribution by increasing the wholesale price $\left(w^{p}<w^{u}\right)$. Further, when $\varphi_{1}=1$, the recycling effort, rents, and wholesale prices are equal, respectively, under different sharing mechanisms.

We try to find the reasonable $\varphi_{1}$ and $\varphi_{2}$ to achieve supply chain coordination. When $g^{I}=g^{i},(i=u p, p, u, C S)$, it is $p^{I}-p^{i}<0$ under U - CS and CS, $\varphi_{1}=\varphi_{2}=0$ under UP CS and $U-C S$ when $\varphi_{1} \in(0,1)$. Therefore, on the basis of cost sharing, the revenue sharing mechanism cannot achieve supply chain coordination.

5.2. Linear Transfer Payment-CS. In this section, we design a contract to achieve supply chain coordination on the basis of cost sharing. The supplier shares a fraction of the cost and obtain transfer payment about the effort from the operator. In order to encourage the supplier to participate actively, the cost sharing ratio should have a lower limit $\varphi_{2}>\left(n \alpha^{2} \lambda^{2} /\left(k \beta\left(\Delta^{2}+3 \Delta \rho+2 \rho^{2}\right)\right)\right)$. A linear transfer payment of recycling effort is adopted to achieve this goal. This can also be seen as

$$
w=\frac{F g}{I(t)},
$$

where $F$ is the transfer payment for unit recycling effort. Here, the wholesale price can be regarded as transfer price which is usually adopted to coordinate decentralized decision within a firm. Under the linear transfer payment CS, the profits of the supplier and operator are

$$
\begin{aligned}
\underset{(p(t), g)}{J_{o}^{F}} & =\int_{0}^{\infty} e^{-\Delta t}\left((u+n p(t)) D(t)-F(t) g-\frac{\varphi_{2} k g^{2}}{2}\right) \mathrm{d} t, \\
\underset{F(t)}{J_{s}^{F}} & =\int_{0}^{\infty} e^{-\Delta t}\left(F(t) g-\frac{\left(1-\varphi_{2}\right) k g^{2}}{2}\right) \mathrm{d} t .
\end{aligned}
$$

The operator first decides the recycling maintenance effort $g$, and the supplier decides the transfer payment $F(t)$. Finally, the operator decides the rent $p(t)$. We use backward induction method to solve this sequential move game. The optimal results are presented in Proposition 8.

Proposition 8. Under the linear transfer payment CS, the equilibrium rent, transfer payment for the unit's recycling effort, and recycling effort are

$$
\begin{aligned}
g^{C F} & =\frac{\lambda \alpha\left((\Delta+2 \rho)(n(\eta-u)+u \beta)+n \Delta \alpha G_{0}\right)-2 F \beta\left(\Delta^{2}+3 \Delta \rho+2 \rho^{2}\right)}{2 k \beta\left(\Delta^{2}+3 \Delta \rho+2 \rho^{2}\right) \varphi_{2}-2 n \alpha^{2} \lambda^{2}}, \\
F & <\frac{\lambda \alpha\left((\Delta+2 \rho)(n(\eta-u)+u \beta)+n \Delta \alpha G_{0}\right)}{2 \beta\left(\Delta^{2}+3 \Delta \rho+2 \rho^{2}\right)}, \\
p^{C F} & =\frac{-n u-u \beta+G n \alpha+n \eta}{2 n \beta} .
\end{aligned}
$$

Proposition 9. The linear transfer payment contract can perfectly coordinate a bicycle sharing SC that focuses on recycling effort. It is evident from the following: $g^{I}=g^{F}, p^{I}=$ $p^{F} \quad$ when $\varphi_{2}=\left(\left(-2 F\left(N_{1}-N_{2}\right)+k \alpha \lambda M_{1}\right) /\left(k \alpha \lambda M_{1}\right)\right)$, $F<\left(\left(k \alpha \lambda M_{1}\right) /\left(2 N_{1}\right)\right)$. The determination of $F$ depends on the bargaining power of the operator and the supplier.

In this contract, the supplier charges a unit selling price from the operator that is equal to its own marginal cost. Therefore, the supplier would not gain any profit by selling bicycle. It would gain entire profit by the transfer payment about the effort from the operator.

The above situations can be summarized in Table 2 .

\section{Numerical Analysis}

In this section, we perform numerical analysis to illustrate the results above. The basic parameter values are presented in Table 3, which are chosen mainly based on the work of
Zhang et al. [11] and satisfy the assumptions mentioned in the section of model formulation.

6.1. Analysis in Integrated and Decentralized Scenarios. With the memory characteristics of the consumers' experience, we try to reveal how consumers' experience, dynamic variable rents, and profits are changing over time when the recycling effort is static.

According to Figure 2, the experience increases over time and tends to be fixed, which is consistent with the rule of human experience. Similarly, the rent increases firstly then tends to be fixed, which depends on consumers' experience. The findings reveal that the operator increases the rent at the early stage then tries to keep rent steady in case the consumers give up using bicycles due to the high cost of the service. Further, comparing the rents between the integrated and decentralized scenarios, we find that the rents in decentralized scenario are higher at the initial stage then 


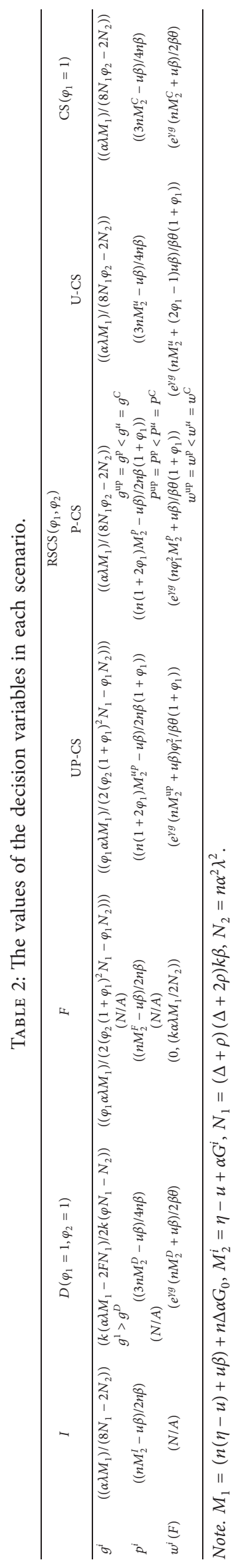


TABLE 3: Basic parameter values.

\begin{tabular}{lc}
\hline Parameter & Value \\
\hline$\eta$ & 20 \\
$\beta$ & 2 \\
$\alpha$ & 1 \\
$\lambda$ & 1 \\
$\rho$ & $2 / 5$ \\
$\Delta$ & $1 / 10$ \\
$k$ & 2 \\
$G_{0}$ & 3 \\
$\theta$ & $1 / 5$ \\
$\gamma$ & 1 \\
$n$ & 1 \\
$u$ & 2 \\
$t$ & 1 \\
\hline
\end{tabular}

lower than those in integrated scenario. The reason is that the growth rate in integrated scenario is faster than that in decentralized scenario. Hence, the consumers benefit from the integrated scenario with low rent at the early stage.

Similarly, profits continue to increase and tend to a fixed value over time when the recycling cost is static. Obviously, the profit in the integrated scenario is more than the profit in the decentralized scenario.

From Figure 3(a), the rent decreases with the decay rate, and this indicates that high decay rate is negative for the operator when consumers have a bad riding experience. The finding tells that the operator should reduce rent to compensate consumers' loss and increase bicycle demand when the decay rate is high. We can also observe that the rent in integrated scenario is less than that in decentralized scenario when the decay rate is low. Figure 3(b) shows that the effort decreases as the decay rate increases, which is consistent with the intuition. In other words, the low decay rate has a positive effect on the operator to invest in recycling effort. As a result, the operator should invest more to face low decay rate in the market. The operator makes corresponding investment strategy (different value of the recycling effort) for different groups of consumers (different decay rate).

Figure 4 shows that the larger the sensitivity of recycling effort, the higher the rent and recycling effort. The reason is that with a large sensitivity, it can bring better riding experience at the same level of effort; the better riding experience which leads to more demand motivates the operator to set higher rent. A sensible income received from high rent enables the operator to invest much recycling effort. On the basis of the analysis above, the operator can increase the rent and the recycling effort with high sensitivity of recycling effort to experience.

It is further found that the rent in integrated scenario is lower than that in decentralized scenario while the recycling effort is higher in integrated scenario. Moreover, the changing trend in integrated scenario is stronger than that in decentralized scenario. It is obvious that the integrated scenario brings more benefits for the consumers (low rent) and the society (high recycling effort).

Similarly, Figures 4 and 5 show that the larger the sensitivity of experience, the higher the rent and recycling effort. The reason is that the larger sensitivity of experience brings more demand with the same riding experience directly which gives the operator an advantage to decide high rent. Then the operator has financial strength support for more recycling effort with high rent. As a result, the operator should set high rent and recycling effort with large sensitivity of experience.

The value of rent and recycling effort in integrated scenario is larger than that in decentralized scenario, respectively. Moreover, as the sensitivity of experience in demand increases, the rent (recycling effort) increases and the increase in integrated scenarios is stronger.

As seen in Figure 6, $(1 / n)$ represents the positive factor that the change of the deposit affects the profit through changing the margin profit; $(1 / \beta)$ represents the negative factor that the change of the deposit affects the profit through changing the demand. When the negative factor is stronger $(\beta<n)$, high deposit brings the operator low profit which deters the investment of the recycling effort; when the positive factor is stronger $(\beta>n)$, high deposit brings the operator high profit which promotes the investment of the recycling effort. The deposit's effect on the recycling effort depends on the power of two factors.

The damage rate $\theta$ only affects the value of the wholesale price, and the recycling effort and rent are not changed due to changes in the damage rate.

6.2. Analysis in RSCS Scenario. In this section, we analyze the impact of share ratios on the differences in decision variables between the four RSCS contracts. Table 4 lists the changes of the differences between decision variables caused by different revenue distribution rules.

Firstly, we find that all values in Table 4 are negative, which verifies Proposition 7 . When the revenue sharing ratio $\varphi_{1}$ is fixed, the more costs (larger $\varphi_{2}$ ) the operator bears, the recycling effort and rents tend to be the same by comparing the rows of Table 4. By comparing the columns in Table 4, the difference of the recycling effort $\Delta g$ and rents $\Delta p$ is gradually diminishing. In other words, the four kinds of contracts are unified into the decentralized scenario when $\varphi_{1}$ and $\varphi_{2}$ gradually tend to 1 .

Figure $7(a)$ depicts the changes about the recycling effort's difference $\Delta g$ with the revenue sharing ratio under four cost-sharing ratios. Figure $7(b)$ depicts the changes about the rent's difference $\Delta p$. It can be seen that the more revenue the operator obtains (larger $\varphi_{1}$ ), the smaller the impact of revenue sharing contracts on the recycling effort and rent (smaller $\Delta g$ and $\Delta p$ ). This shows that the greater ratio the operator has (the larger $\varphi_{1}$ the operator shares), the less effect on the recycling and rent the type of revenuesharing contract has. Moreover, the tendency to change is slow, not linear. When comparing the four cost-sharing ratios, the difference of recycling effort $\Delta g$ becomes smaller with the four cost-sharing ratios. The change of rent is similar to the recycling effort. These conclusions are consistent with the conclusions obtained in Table 4.

Next, we try to find the changes about the differences between wholesale price under the four RSCS contracts in the 


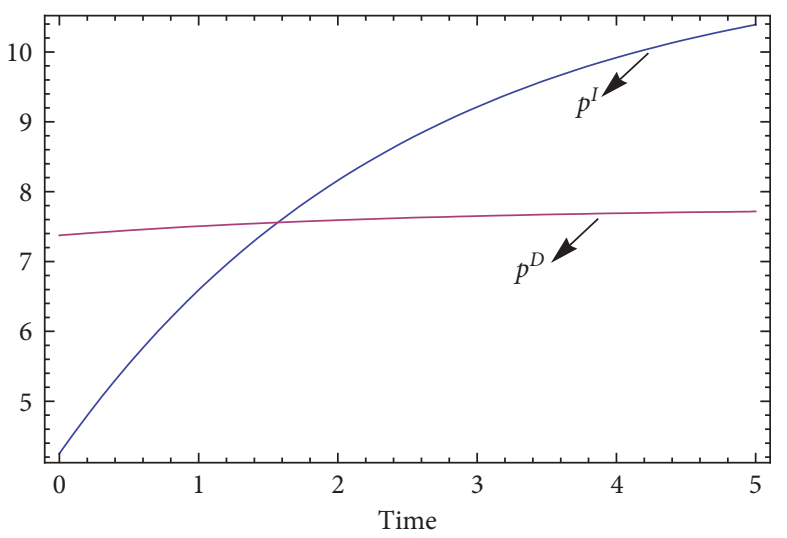

(a)

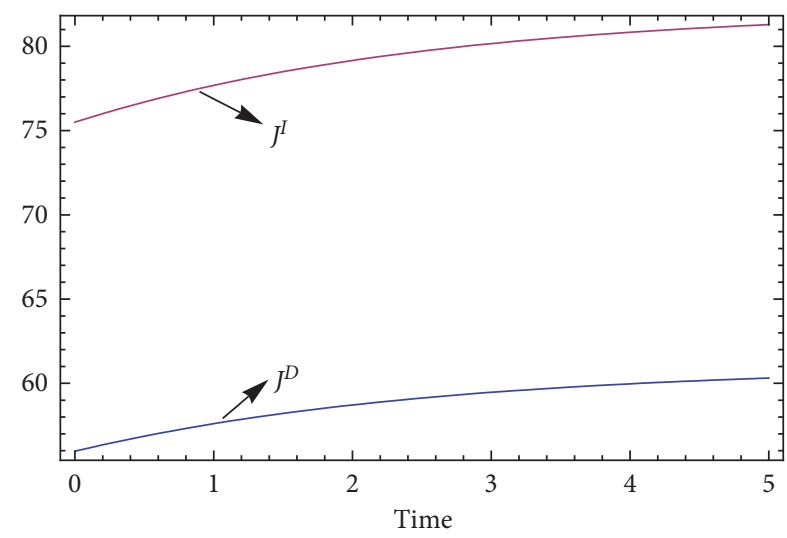

(b)

Figure 2: The impacts of time on $p$ and $J$.

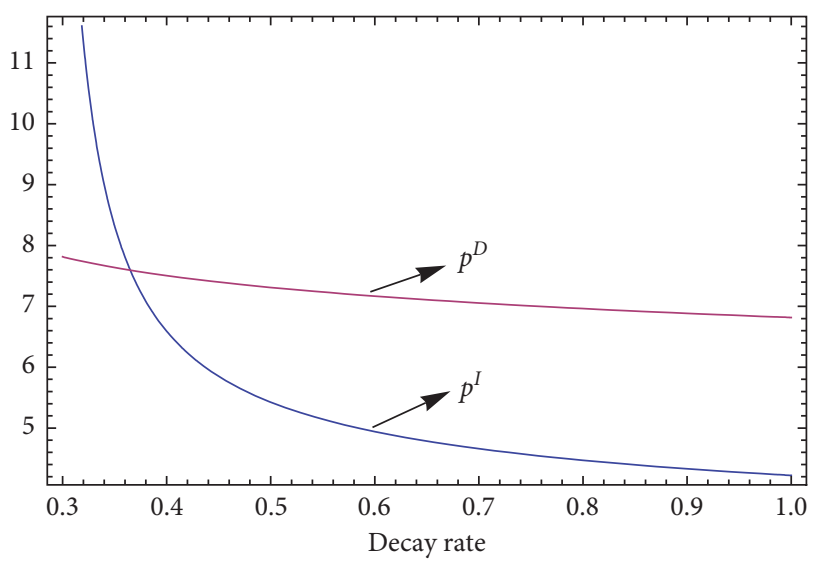

(a)

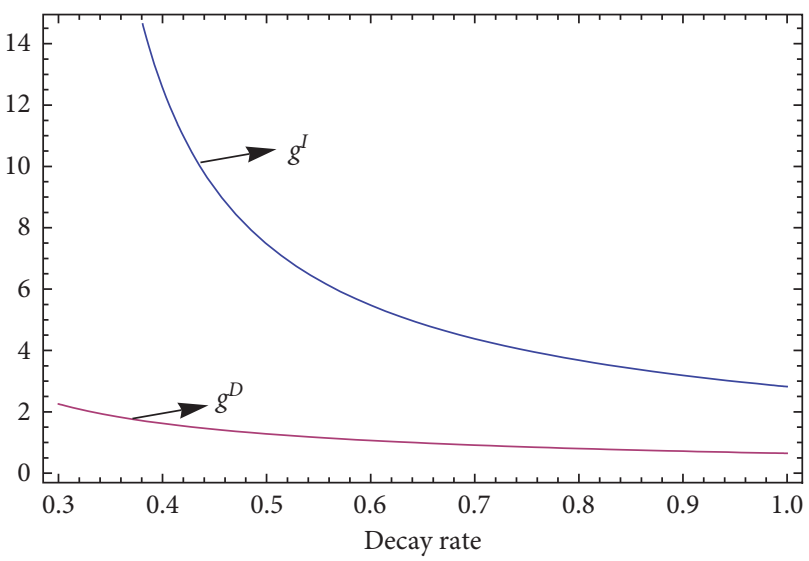

(b)

Figure 3: Impacts of decay rate of consumers' memory on $p$ and $g$.

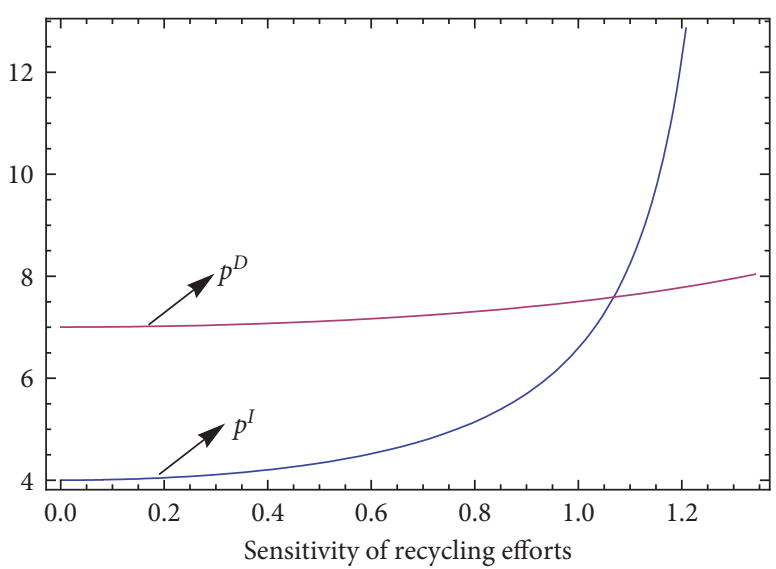

(a)

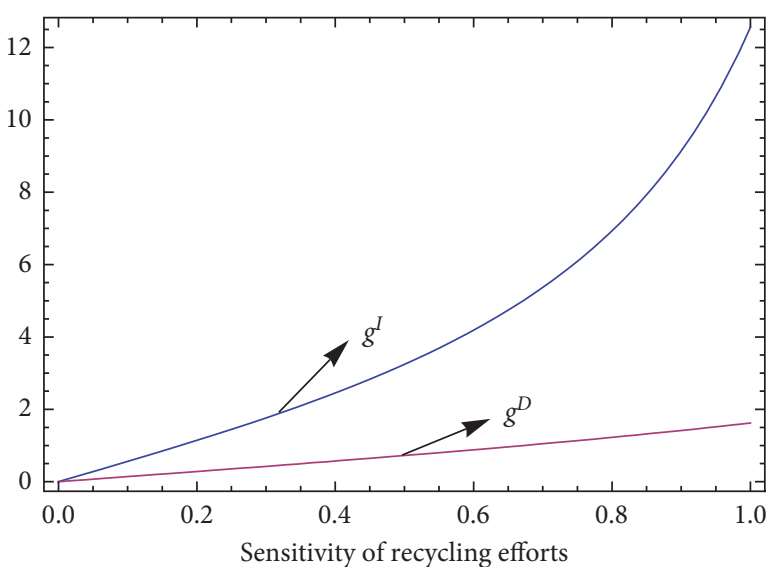

(b)

FIGURE 4: Impacts of sensitivity of recycling effort to experience on $p$ and $g$. 


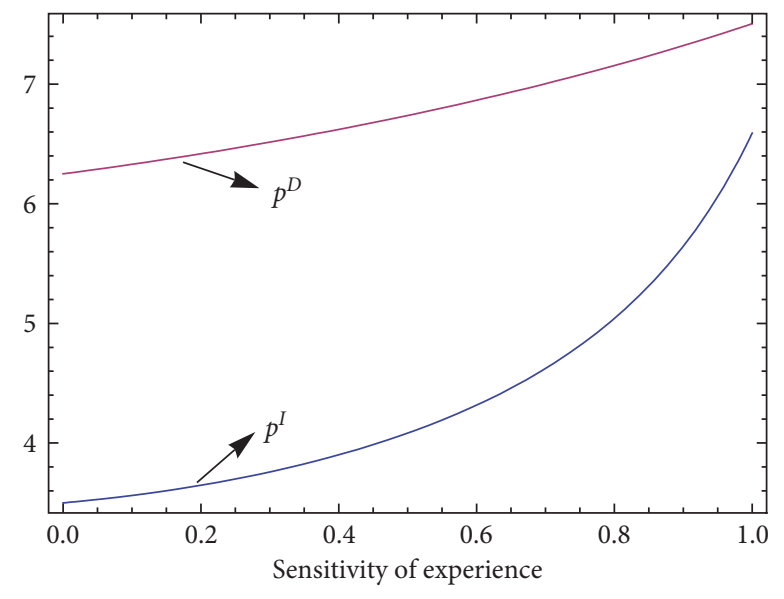

(a)

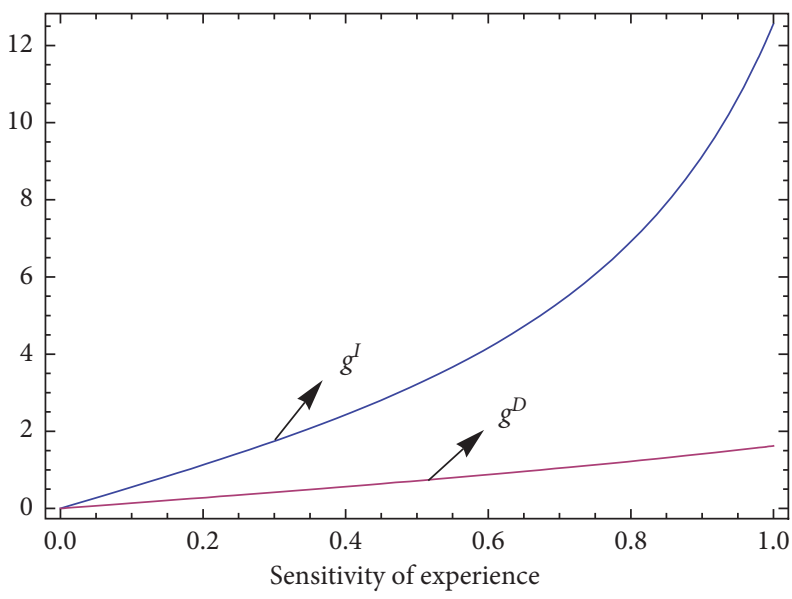

(b)

FIGURE 5: Sensitivity of experience to demand of the bicycle.

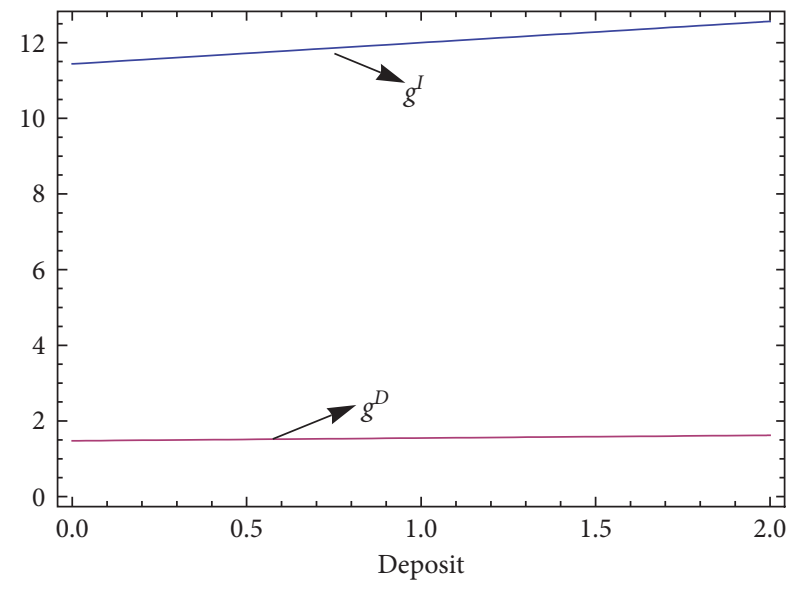

(a)

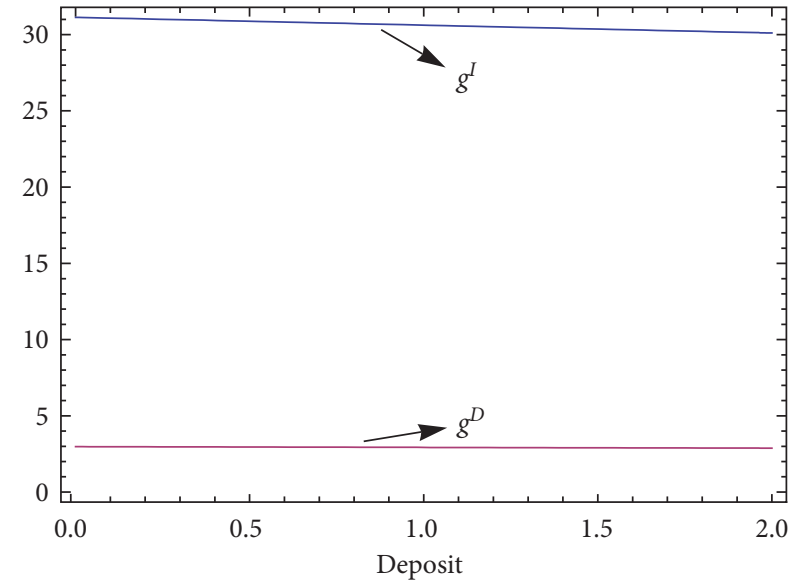

(b)

FIgURE 6: The impacts of the deposit. (a) When $n<\beta$. (b) When $n>\beta$.

TABLE 4: The values of $\Delta g$ and $\Delta p$.

\begin{tabular}{lllll}
\hline$\Delta g$ & $\varphi_{2}=0.3$ & $\varphi_{2}=0.5$ & $\varphi_{2}=0.7$ & $\varphi_{2}=0.9$ \\
\hline$\varphi_{1}=0.1$ & -6.85 & -2.85 & -1.78 & -1.29 \\
$\varphi_{1}=0.3$ & -3.74 & -1.40 & -0.84 & -0.60 \\
$\varphi_{1}=0.5$ & -1.64 & -0.57 & -0.34 & -0.24 \\
$\varphi_{1}=0.7$ & -0.49 & -0.16 & -0.10 & -0.07 \\
$\varphi_{1}=0.9$ & -0.04 & -0.015 & -0.009 & -0.006 \\
\hline$\Delta p$ & & & & \\
\hline$\varphi_{1}=0.1$ & -4.73 & -3.42 & -3.07 & -2.9 \\
$\varphi_{1}=0.3$ & -3.04 & -2.18 & -1.97 & -1.87 \\
$\varphi_{1}=0.5$ & -1.75 & -1.29 & -1.18 & -1.13 \\
$\varphi_{1}=0.7$ & -0.83 & -0.65 & -0.60 & -0.58 \\
$\varphi_{1}=0.9$ & -0.22 & -0.18 & -0.17 & -0.169 \\
\hline
\end{tabular}

Note. $\Delta g=g^{u p}-g^{u}, \Delta p=p^{u p}-p^{u}$.

same way. Let $\Delta w 1=w^{u p}-w^{p}, \quad \Delta w 2=w^{p}-w^{u}$, $\Delta w 3=w^{u}-w^{C}$ and compare the changes about wholesale price with the proportion of revenue sharing.
When we compare the UP-CS and the P-CS, Figure 8(a) shows the changes of the wholesale price difference about the revenue sharing ratio. Figure $8(\mathrm{~b})$ shows the changes of the wholesale price difference about the revenue sharing ratio between P-CS and U-CS. Figure 8(c) is between U-CS and CS. From Figure 8(a), the difference of the wholesale price is increased initially and then decreased. When the revenue sharing ratio $\varphi_{1}$ is large, the supplier under P-CS sets a higher wholesale price with the ratio. From Figure $8(\mathrm{~b})$, when the supplier obtains a large proportion of the revenue (smaller revenue sharing ratio), the differences of the wholesale prices between P-CS and U-CS increase slowly with the revenue sharing ratio, and the difference of the wholesale prices decreases rapidly when the operator obtains a larger proportion of the revenue (larger revenue sharing ratio). In Figures $8(\mathrm{a})$ and $8(\mathrm{~b})$, the wholesale price's differences increase first and then decrease with the revenue sharing ratio $\varphi_{1}$, respectively. It is obvious from Figure 8(c) 


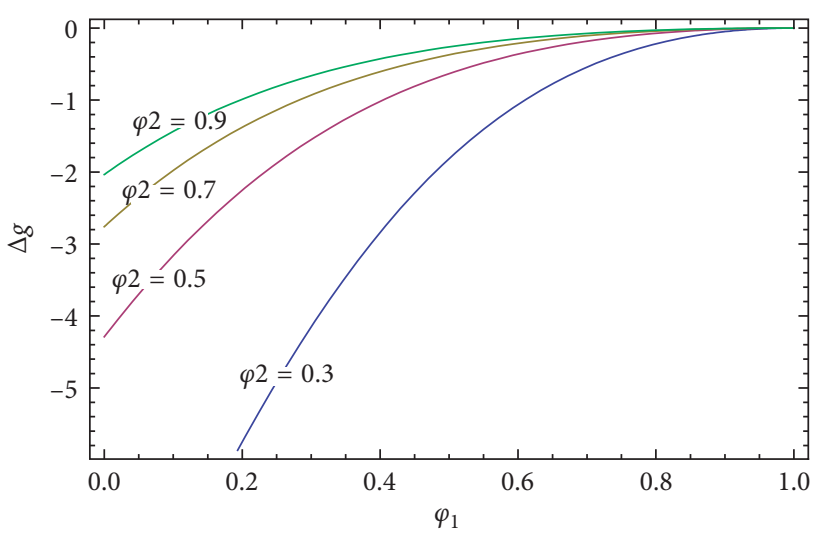

(a)

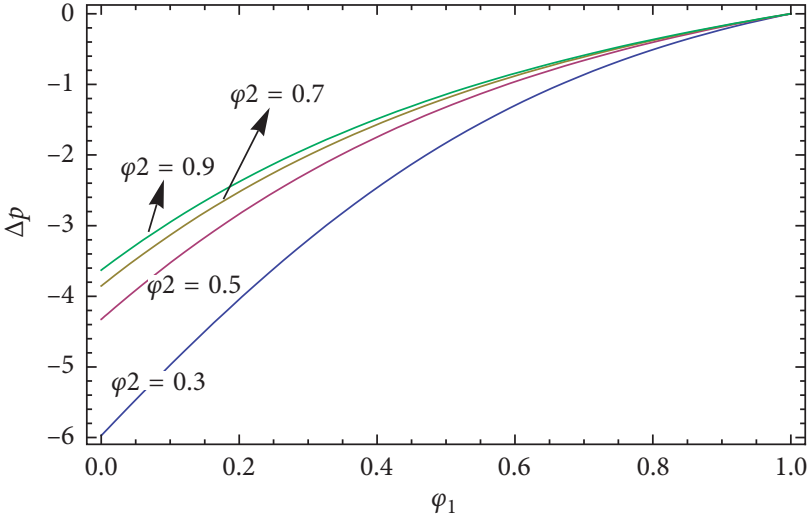

(b)

Figure 7: The impacts of revenue sharing ratio.
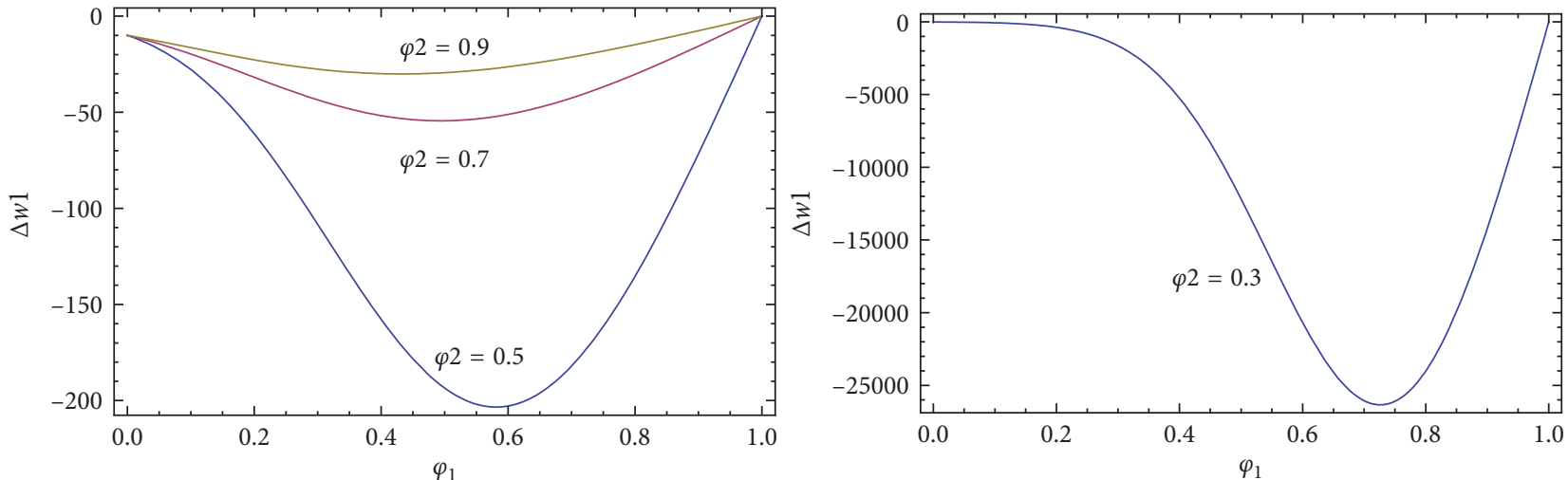

(a)

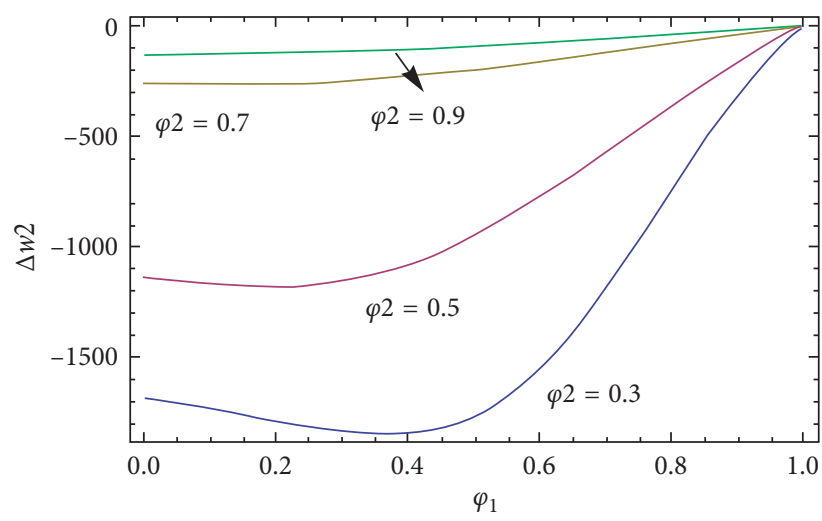

(b)

Figure 8: Continued. 


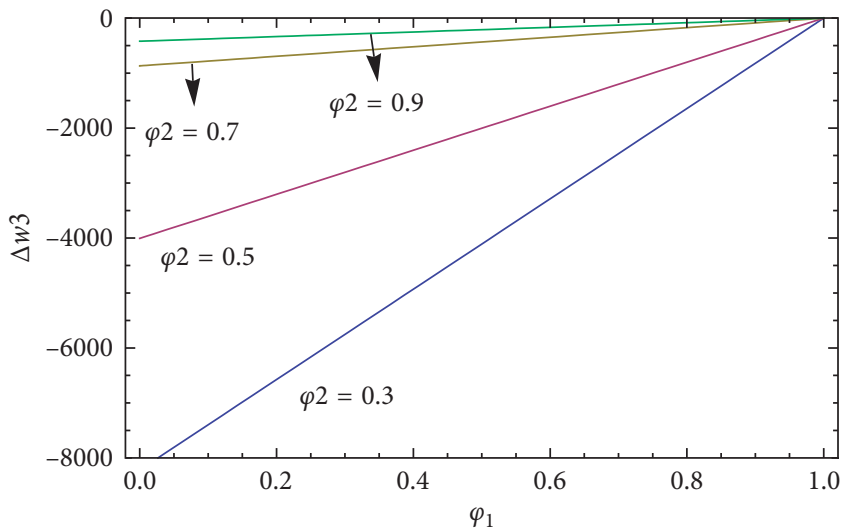

(c)

Figure 8: (a) The impacts of revenue sharing ratio. Note. Since the value of $\varphi_{2}=0.3$ is too large, it is represented by a single graph. (b) The impacts of revenue sharing ratio. (c) The impacts of revenue sharing ratio.

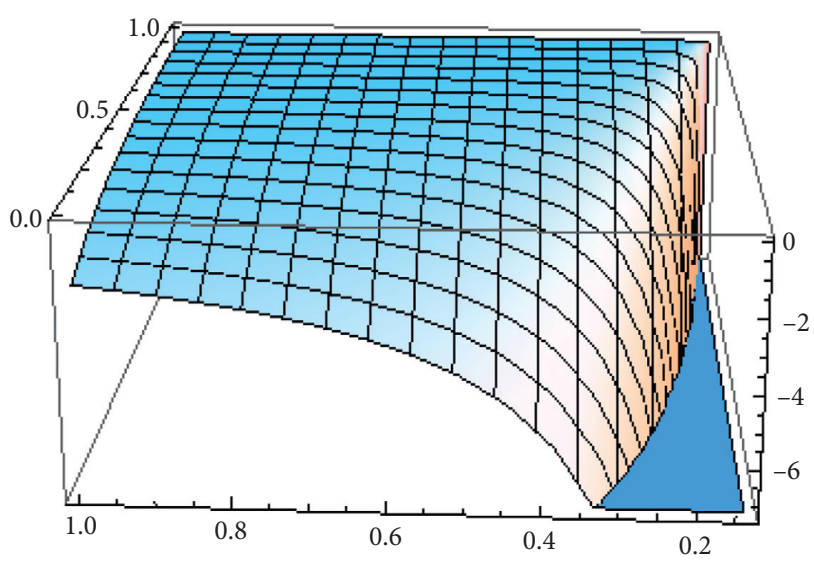

(a)

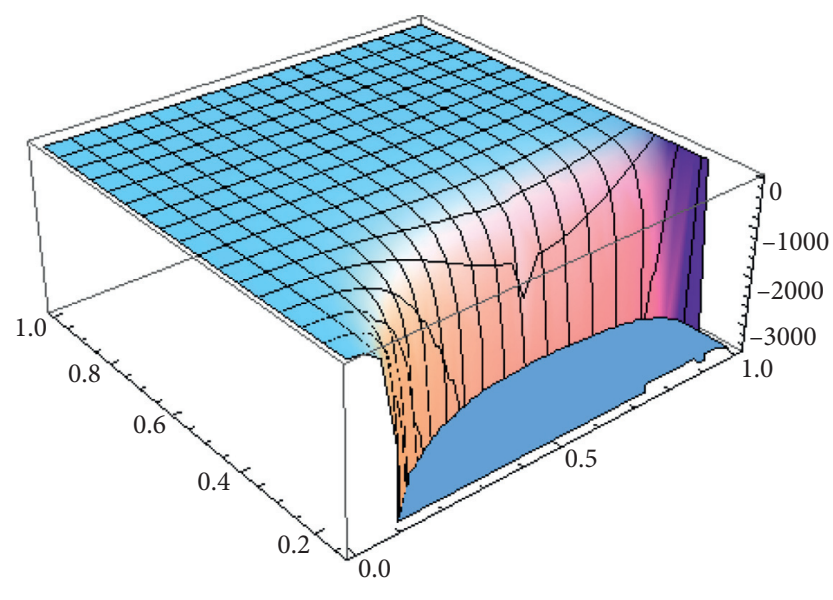

(c)

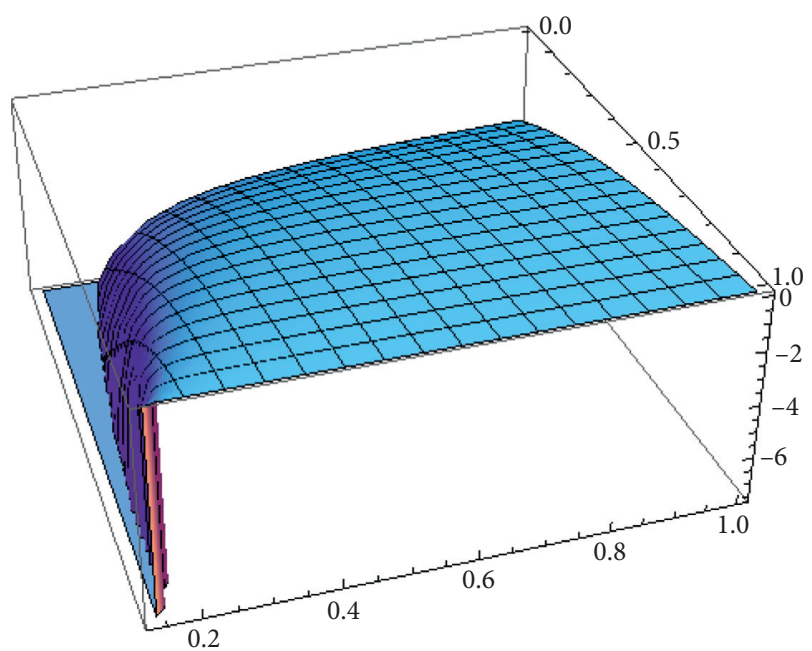

(b)

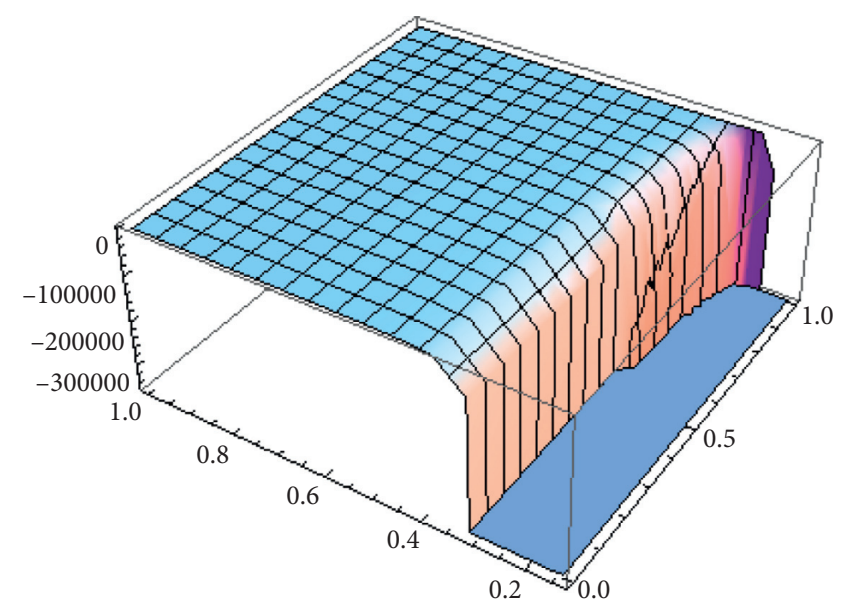

(d)

FIgURE 9: Continued. 


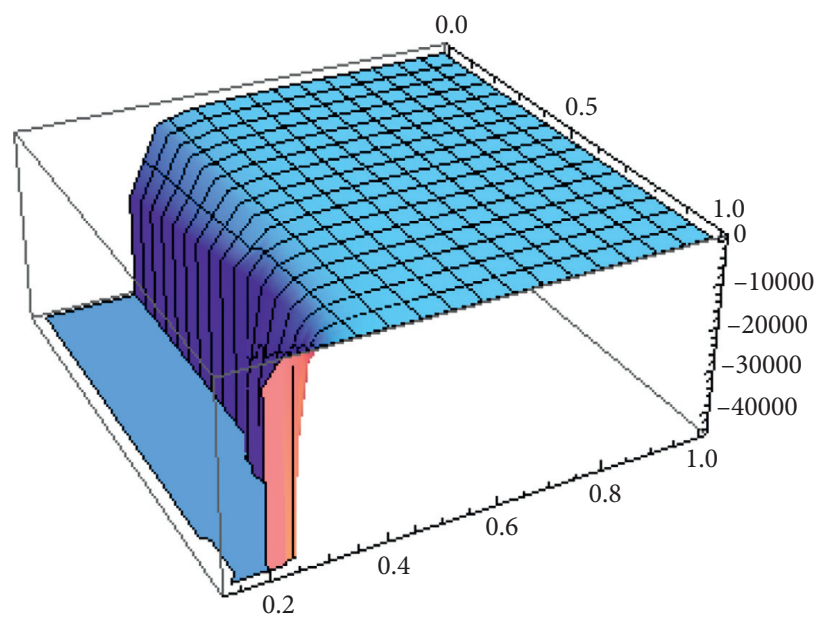

(e)

Figure 9: (a) The impact on $\Delta g$. (b) The impact on $\Delta p$. (c) The impact on $\Delta w 1$. (d) The impact on $\Delta w 2$. (e) The impact on $\Delta w 3$.

that the wholesale price under U-CS is monotonously increasing and gradually the same with the wholesale price under CS.

When the revenue sharing ratio is fixed, the impact of the cost sharing ratio on the wholesale price difference can be observed. As seen from Figure 8, the difference of wholesale prices decreases with the cost-sharing ratio. When the operator bears much recycling costs, the type of revenue sharing contracts has little effect on the wholesale price.

Figure 9 depicts the effects of both the revenue sharing ratio and cost sharing ratio on the differences of decision variables under four RSCS contracts. Obviously, the recycling effort difference decreases with both the share ratios. This conclusion is also applied to rent while the wholesale price situation is somewhat complicated.

Regardless of the change process, when the operator fully possesses the revenue $\left(\varphi_{1}=1\right)$, the RSCS contracts are unified into a cost-sharing contract and the decision variables are equal. This is apparent from Figure 9, and Figure 9 also depicts the impacts of cost-sharing contract changes on the variance of the variables more clearly.

\section{Conclusions}

In this paper, we have designed a closed-loop supply chain model about shared bicycle considering the effect of recycling effort on riding experience under the dynamic scenario. It is a long-term and dynamic process for the operator to provide bicycle service to meet consumers' travel service. The game participants achieve the final balance through dynamic game and interaction, and differential game method can meet this requirement. Specifically, we have considered a two-stage SC, where a bicycle operator is accountable for recovery and maintenance and a bicycle supplier is responsible for new bicycle. We have first analyzed a centralized SC and a decentralized SC then made analysis of parameter sensitivity. Subsequently, we have analyzed four revenue sharing-cost sharing contracts: UP-CS, P-CS, U-CS, and CS. We get the analytical solutions of these models and make a comprehensive analysis and comparison of the results through analytic method and numerical study. Then, we have further designed a contract to achieve supply chain coordination on the basis of cost sharing. The main results of this article are as follows: (i) the operator decides recycling effort according to the characteristics of consumers: much recycling effort with low decay rate of consumers' memory and high sensitivity of experience in demand. (ii) The supplier decides wholesale price according to the sharing revenue (different contract type): a high wholesale price with low sharing revenue to guarantee the profits. (iii) There are no differences between the two contracts (UP-CS and P-CS) for consumer payment and recycling investment; the two contracts (U-CS and CS) are the same conclusion. (iv) The revenue sharingcost sharing contracts based on rent and deposit cannot achieve supply chain coordination, but the linear transfer payment-CS can achieve supply chain coordination.

Our work can be extended from the following directions. One is to consider a dynamic recycling effort which may be changing with time and lead to different results. On the other hand, the differential game based on consumer experience does not consider the influence of random factors. Future research can consider the psychological factors of consumers and establish the stochastic differential equation of consumer experience to make it more realistic. And it is also of great interest to embrace government behavior which focuses on the city management. 


\section{Appendix}

Proposition A.1. In the vertical integrate game, we search for a bounded and continuously differentiable value function $V^{I}(G)$ for which a unique solution for $G(t)$ does exist, and the Hamilton-Jacobi-Bellman (HJB) equation is

$$
\Delta V^{I}=\max _{p}\left\{(u+n p)(\eta+\alpha G-\beta p-u)-\frac{k g^{2}}{2}+\frac{\partial V^{I}}{\partial G}(\lambda g-\rho G)\right\},
$$

because the rent is dynamic, maximization of the right-hand side of the HJB equation with respect to $p$ yields

$$
p^{I}=\frac{-n u+\alpha n G-u \beta+n \eta}{2 n \beta} .
$$
by (1)

The recycling maintenance effort is static and obtained (1)

$$
G=G_{0} e^{-\rho t}+\frac{\lambda g^{I}\left(1-e^{-\rho t}\right)}{\rho} .
$$

Substituting (A.2) and (A.3) in (7), and the maximization of (7) provides the optimal static recycling maintenance effort as follows:

$$
g^{I}=\frac{\lambda \alpha\left((\Delta+2 \rho)(n(\eta-u)+u \beta)+n \Delta \alpha G_{0}\right)}{2 k \beta\left(\Delta^{2}+3 \Delta \rho+2 \rho^{2}\right)-2 n \alpha^{2} \lambda^{2}} .
$$

The proof is complete.

Proposition A.2. To obtain a Stackelberg equilibrium, we first determine the rent $p$ as a function of the wholesale price $w$ and recycling maintenance effort $g$. Let $V_{o}^{D}$ and $V_{s}^{D}$ denote the value functions for the operator and supplier. The operator's HJB equation can be specified as

$$
\Delta V_{o}^{D}=\max _{p}\left\{(u+n p)(\eta+\alpha G-\beta p-u)-w I-\frac{k g^{2}}{2}+\frac{\partial V_{o}^{D}}{\partial G}(\lambda g-\rho G)\right\}
$$

The maximization with respect to $p$ yields the operator's reaction function:

$$
p^{D}(w)=\frac{-n u+\alpha n G+n \eta-\beta\left(u-w \theta e^{-\gamma g}\right)}{2 n \beta} .
$$

Anticipating the retailer's response in (A.6), the supplier's HJB equation is given by

$$
\Delta V_{s}^{D}=\max _{w}\left\{w \theta(\eta+\alpha G-\beta p-u) e^{-\gamma g}+\frac{\partial V_{s}^{D}}{\partial G}(\lambda g-\rho G)\right\}
$$

Performing the maximization on the right-hand side with respect to $w$ yields

$$
w^{D}=\frac{e^{\gamma g}(-n u+\alpha n G+u \beta+n \eta)}{2 \beta \theta} .
$$

Substituting the expression of $w$ above into (A.6) produces

$$
p^{D}=\frac{-3 n u+3 \alpha n G-u \beta+3 n \eta}{4 n \beta} .
$$

Substituting (A.3), (A.8), and (A.9) in (9) and the maximization of (9) provide the optimal static recycling maintenance effort as follows:

$$
g^{D}=\frac{\lambda \alpha\left((\Delta+2 \rho)(n(\eta-u)+u \beta)+n \Delta \alpha G_{0}\right)}{8 k \beta\left(\Delta^{2}+3 \Delta \rho+2 \rho^{2}\right)-2 n \alpha^{2} \lambda^{2}} .
$$

The proof is complete.

\section{Data Availability}

The data used to support the findings of this study are available from the corresponding author upon request.

\section{Conflicts of Interest}

The authors declare that they have no conflicts of interest regarding the publication of this paper.

\section{Authors' Contributions}

Jingxiu Song completed the main work of manuscript writing and revision, including the design of the article, model construction and calculation, and result analysis. Yuan Bian contributed to the process of revising manuscripts, including assisting in adding closed-loop supply chain cases, modifying table clarity, and completing part of language modification. Guangdong Liu assisted in the design of the article, revised, and completed the review and finalization of the manuscript. All authors read and approved the final manuscript. The authors also revised the article after it was accepted. They contributed much to the revised version of the manuscript. 


\section{Acknowledgments}

This research was supported by the Teaching Research Project of Fuyang Normal University (Grant no. 2018JYXM49) and Talent Project of Fuyang Normal University (Grant nos. rcxm202012 and 2020KYQD0008).

\section{References}

[1] D. Çelebi, A. Yörüsün, and H. Işık, "Bicycle sharing system design with capacity allocations," Transportation Research Part B: Methodological, vol. 114, pp. 86-98, 2018.

[2] S. Yan, J.-R. Lin, Y.-C. Chen, and F.-R. Xie, "Rental bike location and allocation under stochastic demands," Computers \& Industrial Engineering, vol. 107, pp. 1-11, 2017.

[3] Z. Wang, Y. Sun, Y. Zeng, and B. Wang, "Substitution effect or complementation effect for bicycle travel choice preference and other transportation availability: evidence from US largescale shared bicycle travel behaviour data," Journal of Cleaner Production, vol. 194, pp. 406-415, 2018.

[4] A. A. Kadri, I. Kacem, and K. Labadi, "A branch-and-bound algorithm for solving the static rebalancing problem in bicycle-sharing systems," Computers \& Industrial Engineering, vol. 95, pp. 41-52, 2016.

[5] Y. Li, W. Y. Szeto, J. Long, and C. S. Shui, "A multiple type bike repositioning problem," Transportation Research Part B: Methodological, vol. 90, pp. 263-278, 2016.

[6] Q. Zhang, J. Zhang, and W. Tang, "Coordinating a supply chain with green innovation in a dynamic setting," $4 O R$, vol. 15, no. 2, pp. 133-162, 2017.

[7] G. Erdoğan, M. Battarra, and R. Wolfler Calvo, "An exact algorithm for the static rebalancing problem arising in bicycle sharing systems," European Journal of Operational Research, vol. 245, no. 3, pp. 667-679, 2015.

[8] P. De Giovanni, "Closed-loop supply chain coordination through incentives with asymmetric information," Annals of Operations Research, vol. 253, no. 1, pp. 133-167, 2016.

[9] S. Taboubi, "Incentive mechanisms for price and advertising coordination in dynamic marketing channels," International Transactions in Operational Research, vol. 26, no. 6, pp. 2281-2304, 2019.

[10] D. Zhang, C. Yu, J. Desai, H. Y. K. Lau, and S. Srivathsan, "A time-space network flow approach to dynamic repositioning in bicycle sharing systems," Transportation Research Part B: Methodological, vol. 103, pp. 188-207, 2017.

[11] J. Zhang, L. Lei, S. Zhang, and L. Song, "Dynamic vs. static pricing in a supply chain with advertising," Computers \& Industrial Engineering, vol. 109, pp. 266-279, 2017.

[12] Z. Liu, K. W. Li, B.-Y. Li, J. Huang, and J. Tang, "Impact of product-design strategies on the operations of a closed-loop supply chain," Transportation Research Part E: Logistics and Transportation Review, vol. 124, pp. 75-91, 2019.

[13] P. De Giovanni, "A joint maximization incentive in closedloop supply chains with competing retailers: the case of spentbattery recycling," European Journal of Operational Research, vol. 268, no. 1, pp. 128-147, 2018.

[14] P. DeMaio, "Bike-sharing: history, impacts, models of provision, and future," Journal of Public Transportation, vol. 12, no. 4, pp. 41-56, 2009.

[15] M. Ricci, "Bike sharing: a review of evidence on impacts and processes of implementation and operation," Research in Transportation Business \& Management, vol. 15, pp. 28-38, 2015.
[16] J.-R. Lin and T.-H. Yang, "Strategic design of public bicycle sharing systems with service level constraints," Transportation Research Part E: Logistics and Transportation Review, vol. 47, no. 2, pp. 284-294, 2011.

[17] R. Nair and E. Miller-Hooks, "Equilibrium design of bicycle sharing systems: the case of Washington DC," EURO Journal on Transportation and Logistics, vol. 5, no. 3, pp. 321-344, 2016.

[18] L. M. Martinez, L. Caetano, T. Eiró, and F. Cruz, “An optimisation algorithm to establish the location of stations of a mixed fleet biking system: an application to the city of Lisbon," Procedia-Social and Behavioral Sciences, vol. 54, pp. 513-524, 2012.

[19] C. Park and S. Y. Sohn, "An optimization approach for the placement of bicycle-sharing stations to reduce short car trips: an application to the city of Seoul," Transportation Research Part A: Policy and Practice, vol. 105, pp. 154-166, 2017.

[20] A. Kaltenbrunner, R. Meza, J. Grivolla, J. Codina, and R. Banchs, "Urban cycles and mobility patterns: exploring and predicting trends in a bicycle-based public transport system," Pervasive and Mobile Computing, vol. 6, no. 4, pp. 455-466, 2010.

[21] M. Bordagaray, L. dell'Olio, A. Fonzone, and Á. Ibeas, "Capturing the conditions that introduce systematic variation in bike-sharing travel behavior using data mining techniques," Transportation Research Part C: Emerging Technologies, vol. 71, pp. 231-248, 2016.

[22] X.-H. Yang, Z. Cheng, G. Chen, L. Wang, Z.-Y. Ruan, and Y.-J. Zheng, "The impact of a public bicycle-sharing system on urban public transport networks," Transportation Research Part A: Policy and Practice, vol. 107, pp. 246-256, 2018.

[23] J. Pucher, R. Buehler, and M. Seinen, "Bicycling renaissance in North America? An update and re-appraisal of cycling trends and policies," Transportation Research Part A: Policy and Practice, vol. 45, no. 6, pp. 451-475, 2011.

[24] D. Chemla, F. Meunier, and R. Wolfler Calvo, "Bike sharing systems: solving the static rebalancing problem," Discrete Optimization, vol. 10, no. 2, pp. 120-146, 2013.

[25] M. Kaspi, T. Raviv, and M. Tzur, "Parking reservation policies in one-way vehicle sharing systems," Transportation Research Part B: Methodological, vol. 62, pp. 35-50, 2014.

[26] N. Wang, Q. He, and B. Jiang, "Hybrid closed-loop supply chains with competition in recycling and product markets," International Journal of Production Economics, vol. 217, pp. 246-258, 2018.

[27] C.-H. Wu and Y.-J. Kao, "Cooperation regarding technology development in a closed-loop supply chain," European Journal of Operational Research, vol. 267, no. 2, pp. 523-539, 2018.

[28] X. Hong, K. Govindan, L. Xu, and P. Du, "Quantity and collection decisions in a closed-loop supply chain with technology licensing," European Journal of Operational Research, vol. 256, no. 3, pp. 820-829, 2017.

[29] R. He, Y. Xiong, and Z. Lin, "Carbon emissions in a dual channel closed loop supply chain: the impact of consumer free riding behavior," Journal of Cleaner Production, vol. 134, pp. 384-394, 2016.

[30] B. C. Giri, A. Chakraborty, and T. Maiti, "Pricing and return product collection decisions in a closed-loop supply chain with dual-channel in both forward and reverse logistics," Journal of Manufacturing Systems, vol. 42, pp. 104-123, 2017.

[31] Z. Miao, K. Fu, Z. Xia, and Y. Wang, "Models for closed-loop supply chain with trade-ins," Omega, vol. 66, pp. 308-326, 2017. 
[32] L. Liu, Z. Wang, L. Xu, X. Hong, and K. Govindan, "Collection effort and reverse channel choices in a closed-loop supply chain," Journal of Cleaner Production, vol. 144, pp. 492-500, 2017.

[33] B. Zheng, C. Yang, J. Yang, and M. Zhang, "Pricing, collecting and contract design in a reverse supply chain with incomplete information," Computers \& Industrial Engineering, vol. 111, pp. 109-122, 2017.

[34] N. M. Modak, N. Modak, S. Panda, and S. S. Sana, "Analyzing structure of two-echelon closed-loop supply chain for pricing, quality and recycling management," Journal of Cleaner Production, vol. 171, pp. 512-528, 2018.

[35] X. Xu, P. He, H. Xu, and Q. Zhang, "Supply chain coordination with green technology under cap-and-trade regulation," International Journal of Production Economics, vol. 183, pp. 433-442, 2017.

[36] J. Xie, L. Liang, L. Liu, and P. Ieromonachou, "Coordination contracts of dual-channel with cooperation advertising in closed-loop supply chains," International Journal of Production Economics, vol. 183, pp. 528-538, 2017.

[37] T.-M. Choi, Y. Li, and L. Xu, "Channel leadership, performance and coordination in closed loop supply chains," International Journal of Production Economics, vol. 146, no. 1, pp. 371-380, 2013.

[38] S. Hu, Y. Dai, Z.-J. Ma, and Y.-S. Ye, "Designing contracts for a reverse supply chain with strategic recycling behavior of consumers," International Journal of Production Economics, vol. 180, pp. 16-24, 2016.

[39] O. Kaya, "Incentive and production decisions for remanufacturing operations," European Journal of Operational Research, vol. 201, no. 2, pp. 442-453, 2010.

[40] S. Saha, I. Nielsen, and I. Moon, "Optimal retailer investments in green operations and preservation technology for deteriorating items," Journal of Cleaner Production, vol. 140, pp. 1514-1527, 2017. 